\title{
Conformational polymorphs and solid-state polymerization of
}

\section{9-(1,3-butadiynyl)carbazole derivatives}

Hideyuki Tabata, Kazunori Kuwamoto and Tsunehisa Okuno*

Department of Material Science and Chemistry, Wakayama University,

Sakaedani, Wakayama, 640-8510, Japan

\begin{abstract}
The

novel

diacetylenes,

9-(5-(4-nitrophenoxy)penta-1,3-diyn-1-yl)-9H-carbazole

(1)

and

4-((5-(9H-carbazol-9-yl)penta-2,4-diyn-1-yl)oxy)benzonitrile (2), were prepared and characterized by crystallographic analyses. Compound $\mathbf{1}$ gave two conformational polymorphs, 1-(I) and 1-(II), whose differences were concluded to originate in intermolecular interactions among nitrophenyl groups. Crystal 1-(I) and 2 had suitable molecular arrangements for solid-state polymerization and polymerized by thermal annealing to give crystalline polydiacetylenes (PDAs). While an arrangement of 1-(II) was unsuitable for the polymerization. The PDAs showed broad absorption from UV to
\end{abstract}


near IR region (ca. $900 \mathrm{~nm}$ ), suggesting effective expansion of $\pi$-conjugated system by carbazolyl groups.

\section{Introduction}

Polymorphs [1-3], which are often obtained in organic solids, give different properties on electric conductivity [4,5], magnetism [6] or solid-state reactivity [7]. Therefore control of molecular arrangements, namely control of polymorphs, is one of the most important subjects in materials chemistry.

A Charge transfer complex of 4,4',5,5'-tetramethyl- $\Delta^{2,2^{\prime}}$-bis-1,3-diselenole (TMTSF) and tetracyanoquinodimethane (TCNQ) is one of the most famous complexes in conducting materials, and it has two polymorphs [8,9]. One forms segregated stacks and shows metallic conductivity. The other makes mixed stacks and acts as a semiconductor. In a case of magnetic materials, p-nitrophenyl nitronyl nitroxide (NPNN) forms four crystal polymorphs [10-13], and only the $\beta$-phase shows ferromagnetism [14].

In a case of solid-state reactions, [2+2] cycloaddition of (E)-3-(2-ethoxyphenyl)acrylic acid [15] is known as a typical example whose reactivity 
and selectivity depend on molecular arrangements [16,17]. The compound gives three polymorphs, $\alpha, \beta$ and $\gamma$-phase. Photodimerization proceeds on $\alpha$ and $\beta$-phase, affording syn head-to-tail and syn head-to-head products, respectively, while $\gamma$-phase does not show any reactivities.

Reactivity in solid-state polymerization of diacetylene derivatives is also known to depend heavily on their molecular arrangements $[18,19]$. Baughman et al. studied many crystal packings of diacetylenes and found out condition for the polymerization [20]. They interpreted crystal packing in terms of stacking intervals $(d)$ and inclination angles $(\phi)$ of diacetylene moiety with their stacking axis. The condition for the polymerization was concluded that molecular stacking satisfied both limitations of $d=3.8-6.8 \AA$ and $\phi=30-65^{\circ}$. (Scheme 1)

Total of ninety four polymorphs for diacetylene derivatives have been reported on the Cambridge Crystallographic Data Centre (CCDC) [21,22], involving pseudo-polymorphs, cyclic compounds and tetraynes. Only a few cases were recognized that polymorphs involve reactive and non-reactive diacetylenes. In the first example reported by Hanson [23], both polymorphs could not polymerize under ambient pressure, but one of polymorphs gave PDAs under high pressure. In another example reported by Hocek et al. [24], one of polymorphs is supposed to form a suitable 
molecular arrangement for solid-state polymerization, but the solid-state reactivity was not discussed. Boughman's work [25] and a recent Lauher's work [26] can satisfy above condition.

In this study, we report preparations of novel diacetylene, $\mathbf{1}$ and $\mathbf{2}$, which carry both a carbazolyl group and an acceptor unit as a substituent. Compound $\mathbf{1}$ gives two conformational polymorphs, 1-(I) and 1-(II), by recrystallization from different solutions, and they showed different reactivity in the solid state. Polymerization of $\mathbf{2}$ is also discussed based on its crystal structure in comparison with the structure of 1-(I). To the best of our knowledge, this study is the third report which treats difference in solid-state polymerization reactivity of diacetylenes under ambient pressure between polymorphs.

\section{Experimental}

\section{2-1 General Procedure.}

1H and 13C NMR spectra were recorded on a JEOL JNM-ECA-400 spectrometer in chloroform- $d$ with tetramethylsilane as an internal standard. IR spectra were recorded on a JASCO FT/IR-6100 spectrometer by using a KBr pellet. UV-Vis-NIR spectra in 
solid state were measured on a HITACHI U-3900 spectrometer equipped with an integrating sphere attachment. Elemental analyses were carried out on a J-SCEINCE LAB MICRO CORDER JM10. Differential scanning calorimetric (DSC) measurements were performed on a SHIMADZU DSC-50 calorimeter. Powder X-ray diffraction (PXRD) data were recorded on a RIGAKU MiniFlex II diffractometer with a monochromatic $\mathrm{Cu} \mathrm{K} \alpha$ radiation at ambient temperature.

Single crystals of $\mathbf{1}$ and $\mathbf{2}$ with sufficient quality for X-ray crystallographic analyses were obtained by slow evaporation from an acetonitrile solution for 1-(I), an acetone solution for 1-(II), or a dichloromethane solution for 2. X-ray crystallographic data of 1-(I), 1-(II) and 2 were obtained at $-180{ }^{\circ} \mathrm{C}$ by a RIGAKU VariMax with RAPID with a multi-layer mirror monochromatic $\mathrm{Cu} \mathrm{K} \alpha$ radiation, a RIGAKU R-AXIS RAPID II with a graphite monochromatic Mo K $\alpha$ radiation and a RIGAKU RAXIS-RAPID with a graphite monochromatic $\mathrm{Cu} \mathrm{K} \alpha$ radiation, respectively. In 1-(II), Friedel pairs were merged because the molecule itself was achiral and because there were not any anomalous scattering effects. All structures were solved by a direct method (SHELXS97) [27], and refined by full-matrix least-squares method (SHELXL97) [27]. The positions of all non-H atoms were obtained from differential Fourier maps and refined anisotropically. All $\mathrm{H}$ atoms were placed at ideal positions $\left(\mathrm{Csp}^{2}-\mathrm{H}=0.95 \AA\right.$; 
methylene $\mathrm{Csp}^{3}-\mathrm{H}=0.99 \AA$ ) and were treated as riding on their parent $\mathrm{C}$ atoms with $U_{\text {iso }}(\mathrm{H})=1.2 U_{\mathrm{eq}}(\mathrm{C})$.

The DFT calculations of $\mathbf{1}$ and 2 were performed on Spartan 04 software (Wavefunction, Inc.) [28] with B3LYP 6-31G(d) level. Crystal structures of 1 and 2 were used as initial structures.

\section{2-2 Materials.}

All chemicals were purchased from Kanto Chemical Co. Ltd. or Sigma Aldrich Co. Ltd. and used without further purification. 9-Ethynyl-9H-carbazole [29], 4-(2-propynyloxy)nitrobenzene and 4-(2-propynyloxy)benzonitrile [30] were prepared according to the reported methods.

\section{9-(5-(4-Nitrophenoxy)penta-1,3-diyn-1-yl)-9H-carbazole (1) [31]}

After a suspension of cupper (I) chloride $(0.37 \mathrm{~g}, 3.6 \mathrm{mmol})$ in acetone $(6.5 \mathrm{ml})$ was degassed by argon bubbling for 30 minutes, TMEDA (185 $\mu 1,1.2 \mathrm{mmol})$ was added to the suspension. It was stirred for 30 minutes, and the supernatant solution was transferred into a mixture of 9-ethynyl-9H-carbazole $(0.61 \mathrm{~g}, 3.2 \mathrm{mmol})$ and 4-(2-propynyloxy)nitrobenzene $(3.61 \mathrm{~g}, 20.4 \mathrm{mmol})$ in acetone $(30 \mathrm{ml})$ at room 
temperature. The solution was stirred for 1 day under an oxygen atmosphere. After removal of the solvent, the residue was extracted with dichloromethane $(250 \mathrm{ml})$. The solution was washed with $5 \%$ ammonium hydroxide $(100 \mathrm{ml})$, and the water layer was extracted twice with dichloromethane $(100 \mathrm{ml})$. The combined organic layer was washed with water $(200 \mathrm{ml})$ and dried over anhydrous sodium sulfate. After removal of the solvent, the residue was purified by column chromatography on a silica gel with a mixed solvent of $n$-hexane and ethyl acetate $(10: 1 \mathrm{v} / \mathrm{v})$ as an eluent, and recrystalized from acetonitrile to give $0.28 \mathrm{~g}$ (yield $24 \%$ ) of 1 as a white powder. $1 \mathrm{H}$ NMR (400 MHz, $\left.\mathrm{CDCl}_{3}\right) \delta: 8.26(\mathrm{~d}, J=9.2 \mathrm{~Hz}, 2 \mathrm{H}), 7.99(\mathrm{~d}, J=7.8 \mathrm{~Hz}, 2 \mathrm{H}), 7.64(\mathrm{~d}, J=7.8 \mathrm{~Hz}, 2 \mathrm{H})$, $7.50(\mathrm{t}, J=7.8 \mathrm{~Hz}, 2 \mathrm{H}), 7.36(\mathrm{t}, J=7.8 \mathrm{~Hz}, 2 \mathrm{H}), 7.10(\mathrm{~d}, J=9.2 \mathrm{~Hz}, 2 \mathrm{H}), 5.02(\mathrm{~s}, 2 \mathrm{H})$ ppm. 13C NMR (100 MHz, $\left.\mathrm{CDCl}_{3}\right) \delta: 162.29,142.16,140.09,127.07,125.92,123.82$, $123.10,120.54,114.98,111.64,77.46,72.88,68.85,61.20,57.16$ ppm. IR (KBr pellet, $\left.\mathrm{cm}^{-1}\right)$ : 2241 and $2178\left(v_{\mathrm{C} \equiv \mathrm{C}}\right), 1513$ and $1343\left(v_{\mathrm{NO}_{2}}\right)$. Elemental Anal. Calcd for $\mathrm{C}_{23} \mathrm{H}_{14} \mathrm{~N}_{2} \mathrm{O}_{3}$ : C, 75.40; H, 3.85; N, 7.65. Found: C, 75.33; H, 3.91; N 7.64.

\section{4-((5-(9H-Carbazol-9-yl)penta-2,4-diyn-1-yl)oxy)benzonitrile (2) [31]}

The compound $\mathbf{2}$ was prepared by a similar procedure to $\mathbf{1}$ with 9-ethynyl-9H-carbazole $(1.20 \mathrm{~g}, 6.30 \mathrm{mmol})$ and 4-(2-propynyloxy)benzonitrile (4.95 g, 
$31.5 \mathrm{mmol})$. The crude material was purified by column chromatography to give $1.07 \mathrm{~g}$ (yield $49 \%$ ) of 2 as a white powder. $1 \mathrm{H} \mathrm{NMR}\left(400 \mathrm{MHz}, \mathrm{CDCl}_{3}\right) \delta: 7.99(\mathrm{~d}, J=7.9 \mathrm{~Hz}$, 2H), $7.65(\mathrm{~d}, J=7.9 \mathrm{~Hz}, 2 \mathrm{H}), 7.64(\mathrm{~d}, J=8.5 \mathrm{~Hz}, 2 \mathrm{H}), 7.50(\mathrm{t}, J=7.9 \mathrm{~Hz}, 2 \mathrm{H}), 7.36$ (t, $J=7.9 \mathrm{~Hz}, 2 \mathrm{H}), 7.09(\mathrm{~d}, J=8.5 \mathrm{~Hz}, 2 \mathrm{H}), 4.97(\mathrm{~s}, 2 \mathrm{H}) \mathrm{ppm} .13 \mathrm{C}$ NMR (100 MHz, $\left.\mathrm{CDCl}_{3}\right) \delta: 160.63,140.11,134.05,127.06,123.81,123.08,120.53,118.97,115.63$,

111.63, 105.01, 77.66, 72.68, 68.72, 61.22, 56.81 ppm. IR (KBr pellet, $\mathrm{cm}^{-1}$ ): 2241 and $2175\left(v_{\mathrm{C} \equiv \mathrm{C}}\right), 2223\left(v_{\mathrm{C} \equiv \mathrm{N}}\right)$. Elemental Anal. Calcd for $\mathrm{C}_{24} \mathrm{H}_{14} \mathrm{~N}_{2} \mathrm{O}: \mathrm{C}, 83.22 ; \mathrm{H}, 4.07 ; \mathrm{N}$, 8.09. Found: C, 83.28; H, 4.19; N, 8.00.

\section{Solid-state Polymerization of 1 and 2}

Solid-state polymerization of the monomers 1-(I) and 2 was carried out by thermal annealing in an electric oven. The powdered monomers were sealed into glass tubes with exchange gas of argon.

\section{Results and discussion}

The diacetylene derivatives $\mathbf{1}$ and $\mathbf{2}$ were prepared by Hay coupling reactions [31] of 
9-ethynyl-9H-carbazole with excess of 4-(2-propynyloxy)nitrobenzene and 4-(2-propynyloxy)benzonitrile, respectively, as shown in Scheme 2.

The diacetylene derivative 1 gave two conformational polymorphs, 1-(I) and 1-(II). Polymorph 1-(I) was obtained as pale blue platelet crystals by recrystallization from an acetonitrile solution, while polymorph 1-(II) was given as colorless needles by recrystallization from an acetone solution. Either crystal could be obtained independently judged by powder X-ray diffraction (PXRD). A phase transition between the polymorphs could not be observed by DSC measurements. The compound 2 gave suitable crystals for X-ray diffraction by recrystallization from a dichloromethane solution. The crystal structures of 1-(I), 1-(II) and 2 are shown in Figure 1, 2 and 3, respectively. The crystallographic data are listed in Table 1, and the selected bond lengths and angles were summarized in Table 2. The optimized structures for $\mathbf{1}$ and $\mathbf{2}$ obtained by DFT calculations are shown in Figure 4.

Figure 1(a) and 2(a) show the asymmetric units of 1-(I) and 1-(II), respectively. In both polymorphs, there is one crystallographically independent molecule and both molecules have almost similar bond lengths and angles, which were consistent with those reported ones [32-34]. Although pentadiynylcarbazolyl (N1/C1-C17) and nitrophenoxymethyl $(\mathrm{C} 17-\mathrm{C} 23 / \mathrm{N} 2 / \mathrm{O} 1-\mathrm{O} 3)$ parts have a planar structure in both 
polymorphs, a significant structural difference is recognized at the dihedral angle between the carbazolyl $(\mathrm{N} 1 / \mathrm{C} 1-\mathrm{C} 12)$ and nitrophenyl (C18-C23) groups. The angles are $43.45(8)^{\circ}$ for $\mathbf{1}$-(I) and $7.71(11)^{\circ}$ for $\mathbf{1}$-(II), indicating the molecules in $\mathbf{1}$-(I) and 1-(II) have twist or planar forms, respectively.

Figure 4(a) shows the optimized structure for 1. DFT calculations were performed with both crystal structures as an initial structure, but both calculations converged to the same structure. The bond distances and angles of the optimized structure are almost consistent with those of observed in both polymorphs. However, the dihedral angle between the carbazolyl and nitrophenyl groups was calculated to be ca. $90^{\circ}$, showing a large difference from the observed values. This is presumably because rotation barrier of diacetylenic moiety is very small and because the dihedral angle of the molecule is fairly affected by crystal packing.

Columnar structures along the $a$ axis are formed both in 1-(I) and 1-(II) as shown in Figure 1(b) and 2(b). Remarkable contacts could not be observed between the columns. Stacking intervals $(d)$ of the diacetylene moieties (C13-C16) are 4.8672(3) $\AA$ in 1-(I) and 3.8534(2) $\AA$ in 1-(II). Dihedral angles of the carbazolyl group (N1/C1-C12) with the plane $\left(\mathrm{C} 13 / \mathrm{C} 16 / \mathrm{C} 13^{\mathrm{i}} / \mathrm{C} 16^{\mathrm{i}}\right)$ are $60.21(6)^{\circ}$ for 1 -(I) and $87.79(8)^{\circ}$ for 1 -(II) [symmetry code: (i) $x+1, y, z$ ]. Significant contacts between the carbazolyl rings within 
the stacks could not be recognized. Inclination angles of the diacetylene moiety with the stacking axis $(\phi)$ are $53.00(7)^{\circ}$ for $\mathbf{1}$-(I) and $71.15(12)^{\circ}$ for $\mathbf{1}$-(II). These relative arrangements indicate that the arrangement in crystal 1-(I) is suitable for solid-state polymerization and that it in crystal 1-(II) is unsuitable for the polymerization, judged by the Baughman's notation.

Figure 1(c) and 2(c) show projection to the nitrophenyl planes. In 1-(I), the nitrophenyl groups make contacts within the stacks, where the distances are 3.367(4) $\AA$ for $\mathrm{N} 2 \cdots \mathrm{C} 19^{\mathrm{i}}$ and $3.347(4) \AA$ for $\mathrm{C} 22 \cdots \mathrm{O} 1^{\mathrm{i}}$. In 1-(II), the nitrophenyl groups make rather strong contact, where the distances are 3.290(6) $\AA$ for $\mathrm{C} 21 \cdots \mathrm{O} 3^{\mathrm{i}}$. Judging from both stacking structures, effective interactions work in 1-(II) rather than 1-(I). Polar local structures are formed in 1-(I), which are thought to be favorable in acetonitrile.

Crystal 2 have one crystallographically independent molecule as shown in Figure 3(a). The bond lengths and angles are almost similar with those of crystal 1-(I). The structures of pentadiynylcarbazolyl (N1/C1-C17) and cyanophenoxymethyl groups (C17-C24/N2/O1) have a planar structure. The dihedral angle of the carbazolyl group (N1/C1-C12) with cyanophenyl group $(\mathrm{C} 18-\mathrm{C} 23)$ is $68.14(6)^{\circ}$, which shows that crystal 2 has a twisted form as similar to 1 -(I).

Crystal 2 makes a columnar structure along the $a$ axis as shown in Figure 3(b), 
where stacking intervals $(d)$ of the diacetylene moiety (C13-C16) are 4.9950(3) $\AA$. Remarkable contacts could not be detected between the columnar stacks. Dihedral angle of the carbazolyl group $(\mathrm{N} 1 / \mathrm{C} 1-\mathrm{C} 12)$ with the plane $\mathrm{C} 13 / \mathrm{C} 16 / \mathrm{C} 13^{\mathrm{i}} / \mathrm{C} 16^{\mathrm{i}}$ [Symmetry code: (i) $x+1, y, z]$ is $61.10(5)^{\circ}$, which is similar to that of $\mathbf{1}$-(I) rather than $\mathbf{1}$-(II). Significant contacts between the carbazolyl rings within the stacks could not be recognized. Inclination angle of the diacetylene moiety with the stacking axis $(\phi)$ is $48.44(6)^{\circ}$. These stacking parameters, which are similar with those of 1-(I), indicating that the molecular arrangement of crystal $\mathbf{2}$ is also suitable for solid-state polymerization.

Figure 3(c) shows the structure of side chains projected onto a cyanophenyl plane. The cyanophenyl groups are found to have little contact, although the nearest distance is 3.370(3) $\AA$ between C22 and C19. Crystal 1-(I) and 2 have two structural similarities, twisted molecular structures and less effective $\pi-\pi$ interactions between side groups. The reason for formation of suitable molecular arrangements for the solid-state polymerization may be realized by less effective interaction between acceptor units in these cases.

The diacetylene derivatives 1-(I) and 2 showed solid-state polymerization reactivity by thermal annealing or UV irradiation. The powdered crystals of 1-(I) 
polymerized smoothly above $140{ }^{\circ} \mathrm{C}$, and polymerization of 2 proceeded above $120^{\circ} \mathrm{C}$. The progress of polymerization was monitored by the intensities of $v_{\mathrm{C}=\mathrm{C}}$ of the monomers. The polymerization of 1-(I) was found to be fully completed in ca. 300 hours judged by disappearance of $v_{\mathrm{C} \equiv \mathrm{C}}$ signals $\left(2241,2178 \mathrm{~cm}^{-1}\right)$ of the monomers. The obtained polymer gave a novel signal at $2126 \mathrm{~cm}^{-1}$, which was assigned to $v_{\mathrm{C} \equiv \mathrm{C}}$ signal of PDA backbone. The polymerization of 2 was also found to be fully completed in about 300 hours judged by disappearance of $v_{\mathrm{C} \equiv \mathrm{C}}$ signals $\left(2241,2175 \mathrm{~cm}^{-1}\right)$ of the monomers. The obtained polymer gave a novel signal at $2128 \mathrm{~cm}^{-1}$, which was assigned to $v_{\mathrm{C} \equiv \mathrm{C}}$ signal of PDA backbone. The obtained polymers 1-(I) and 2 were insoluble in common organic solvents such as chloroform, acetone and tetrahydrofuran, and were crystalline solids judged by powder X-ray diffraction (PXRD) patterns. (Figure S8 and S9)

Both polymers showed broad absorption bands from UV to near IR region, and the absorption edges reached to ca. $900 \mathrm{~nm}$. (Figure S5) The excitonic transitions are usually observed around $600 \mathrm{~nm}$ in PDAs [35,36]. While in a case of poly-(1-( $N$-carbazolyl)penta-1,3-diyn-5-ol) (poly-CPDO), an excitonic transition could not be observed and absorption edge of inter-band transition reached to ca. $800 \mathrm{~nm}$ $[37,38]$. The broad absorption bands observed in poly-1-(I) and poly-2 could be 
assigned to inter-band transition as well as that of poly-CPDO. Optical band gaps of poly-1-(I) and poly-2 were estimated to ca. $1.8 \mathrm{eV}$, which were much smaller than that of poly-CPDO. The conjugated $\pi$ system of the PDA main chain is thought to lie on the $\mathrm{C} 13 / \mathrm{C} 16 / \mathrm{C} 13^{\mathrm{i}} / \mathrm{C} 16^{\mathrm{i}}$ plane. The dihedral angles of carbazolyl group and the plane are $60.21(6)^{\circ}$ for $1-(\mathrm{I})$ and $61.10(5)^{\circ}$ for 2 . While that of CPDO is ca. $89^{\circ}$ [37]. The smaller values supported that the carbazolyl group and PDA main chain could conjugate more effectively. The obtained polymers were insoluble in common organic solvents. High degree of the polymerization can also explain the expansion of the conjugated system.

\section{Conclusion}

We have succeeded in preparation of novel diacetylene derivatives $\mathbf{1}$ and $\mathbf{2}$ which carry a carbazolyl group and an electron acceptor unit as a substituent. Compound 1 had two conformational polymorphs, 1-(I) and 1-(II), which were concluded to be formed by different intermolecular interactions among the nitrophenyl groups. Crystal 1-(I) and 2 have suitable arrangements for solid-state polymerization, and the polymerization proceeded by thermal annealing to give crystalline PDAs. Although strong correlation between main chain of the PDAs and the pendant groups 
could not be observed, absorption edges of the PDAs in the UV-Vis-NIR spectra reached to ca. $900 \mathrm{~nm}$, suggesting effective expansion of $\pi$-conjugated system by carbazolyl groups.

\section{Acknowledgment}

This work was supported by Adaptable and Seamless Technology Transfer Program through Target-driven R\&D from Japan Science and Technology Agency (JST). 


\section{Reference}

1. J. Bernstein, J. In Polymorphism in Molecular Crystals; Oxford University Press: Oxford, 2002; Chapter 5, pp 151-187.

2. A. Nangia, Acc. Chem. Res. 41 (2008) 595.

3. L. Yu, Acc. Chem. Res. 43 (2010) 1257.

4. M. Mas-Torrent, C. Rovira, Chem. Rev. 111 (2011) 4833.

5. J.E. Anthony, Angew. Chem., Int. Ed. 47 (2008) 452.

6. Q. Ye, T. Akutagawa, S. Noro, T. Nakamura, R.-G. Xiong, Cryst. Growth Des. 10 (2010) 4856.

7. K. Biradha, R. Santra, Chem. Soc. Rev. 42 (2013) 950.

8. K. Bechgaard, T.J. Kistenmacher, A.N. Bloch, D.O. Cowan, Acta Crystallogr., Sect. B: Struct. Crystallogr. Cryst. Chem. 33 (1977) 417.

9. T.J. Kistenmacher, T.J. Emge, A.N. Bloch, D.O. Cowan, Acta Crystallogr., Sect. B: Struct. Crystallogr. Cryst. Chem. 38 (1982) 1193.

10. P.-M. Allemand, C. Fite, G. Srdanov, N. Keder, F. Wudl, P. Canfield, Synthetic Metals 43 (1991) 3291.

11. K. Awaga, T. Inabe, U. Nagashima, Y. Maruyama, Y. J. Chem. Soc. Chem. Commun. 68 (1989) 1617.

12. M. Kinoshita, Jpn. J. Appl. Phys. 33 (1994) 5718.

13. M. Tamura, D. Shiomi, Y. Hosokoshi, N. Iwasawa, K. Nozawa, M. Kinoshita, H. Sawa, R. Kato, Mol. Cryst. Liq. Cryst. Sci. Technol., Sect. A 232 (1993) 45.

14. M. Tamura, Y. Nakazawa, D. Shiomi, K. Nozawa, Y. Hosokoshi, M. Ishikawa, M. Takahashi, M. Kinoshita, Chem. Phys. Lett. 186 (1991) 401.

15. G.M.J. Schmidt, Pure Appl. Chem. 27 (1971) 647. 
16. M.D. Cohen, G.M.J. Schmidt, F.I. Sonntag, J. Chem. Soc. (1964) 2013.

17. G.M.J. Schmidt, J. Chem. Soc. (1964) 2021.

18. G. Wegner, Z. Naturforsch. B24 (1969) 824.

19. V. Enkelmann, In Advances in Polymer Science; Springer-Verlag: Berlin, 1984; pp $91-136$.

20. R.H. Baughman, J. Polym. Sci., Polym. Phys. Ed. 12 (1974) 1511.

21. Database searches were carried out using CSD version 5.36 (November 2014 update; 717,876 entries) using the program ConQuest (ver. 1.17).

22. F.H. Allen, Acta Crystallogr., Sect. B: Struct. Crystallogr. Cryst. Chem. 58 (2002) 380.

23. A.W. Hanson, Acta Crystallogr., Sect. B: Struct. Crystallogr. Cryst. Chem. 31 (1975) 831.

24. M. Hocek, H. Dvořáková, I. Císařová, Collect. Czech. Chem. Commun. 67 (2002) 1560.

25. R.B. Wilson, E.N. Duesler, D.Y. Curtin, I.C. Paul, R.H. Boughman, A.F. Preziosi, J. Am. Chem. Soc. 104 (1982) 509.

26. Te-Jung Hsu, F.W. Fowler, J.W. Lauher, J. Am. Chem. Soc. 134 (2012) 142.

27. G.M. Sheldrick, Acta Crystallogr., Sect. A: Found. Crystallogr. 64 (2008) 112.

28. J. Kong, C.A. White, A.I. Krylov, C.D. Sherrill, R.D. Adamson, T.R. Furlani, M.S. Lee, A.M. Lee, S.R. Gwaltney, T.R. Adams, C. Ochsenfeld, A.T.B. Gilbert, G.S. Kedziora, V.A. Rassolov, D.R. Maurice, N. Nair, Y. Shao, N.A. Besley, P.E. Maslen, J.P. Dombroski, H. Daschel, W. Zhang, P.P. Korambath, J. Baker, E.F.C. Byrd, T. Van Voorhis, M. Oumi, S. Hirata, C.-P. Hsu, N. Ishikawa, J. Florian, A. Warshel, B.G. Johnson, P.M.W. Gill, M. Head-Gordon, J.A. Pople, J. Computational Chem. 
$21(2000) 1532$.

29. C. Cuniberti, G. Dellepiane, P. Piaggio, R. Franco, G.F. Musso, C. Dell'Erba, G. Garbarino, Chem. Mater. 8 (1996) 708.

30. M. Kanagawa, T. Okuno, Acta Crystallogr., Sect. E 71 (2015) 097.

31. A.S. Hay, J. Org. Chem. 27 (1962) 3320.

32. H. Matsuda, H. Nakanishi, T. Hosomi, M. Kato, Macromolecules 21 (1988) 1238.

33. J.J. Mayerle, M.A. Flandera, Acta Crystallogr., Sect. B: Struct. Crystallogr. Cryst. Chem. 34 (1978) 1374.

34. H. Tabata, T. Okuno, Acta Crystallogr., Sect. E 68 (2012) o828.

35. N.S. Sariciftci, B. Kraabel, C.H. Lee, K. Pakbaz, A.J. Heeger, D.J. Sandman, Phys. Rev. B 50 (1994) 12044.

36. G. Barcza, Ö. Legeza, F. Gebhard, R.M. Noack, Phys. Rev. B 81 (2010) 045103.

37. H. Matsuda, H. Nakanishi, N. Minami, M. Kato, Mol. Cryst. Liq. Cryst. 160 (1988) 241.

38. K. Ichimura, H. Matsuda, H. Nakanishi, T. Kobayashi, Phys. Rev. B 47 (1993) 6250. 
(a)

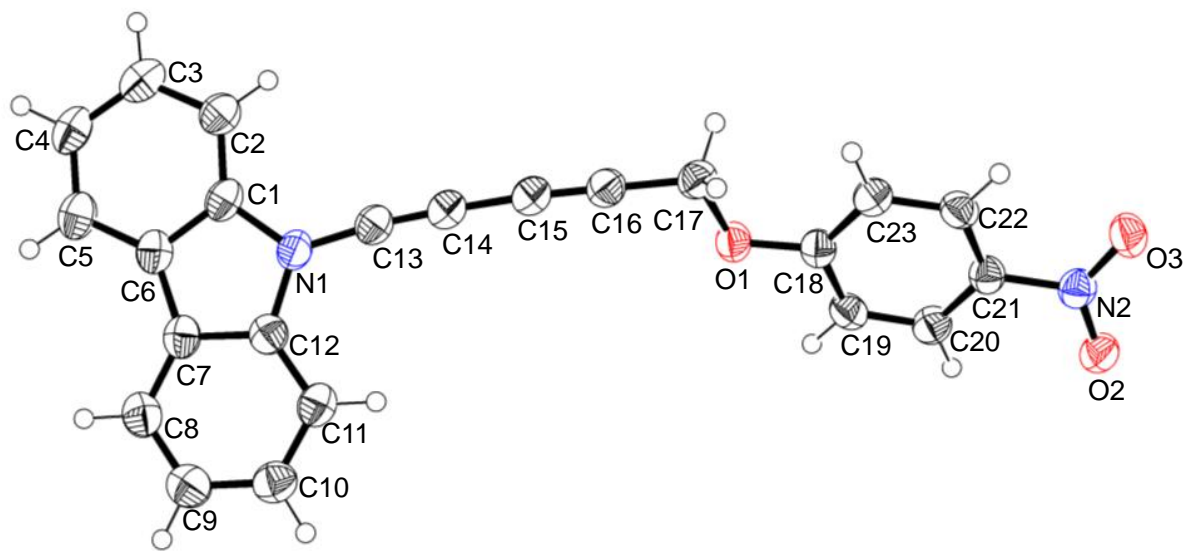

(b)

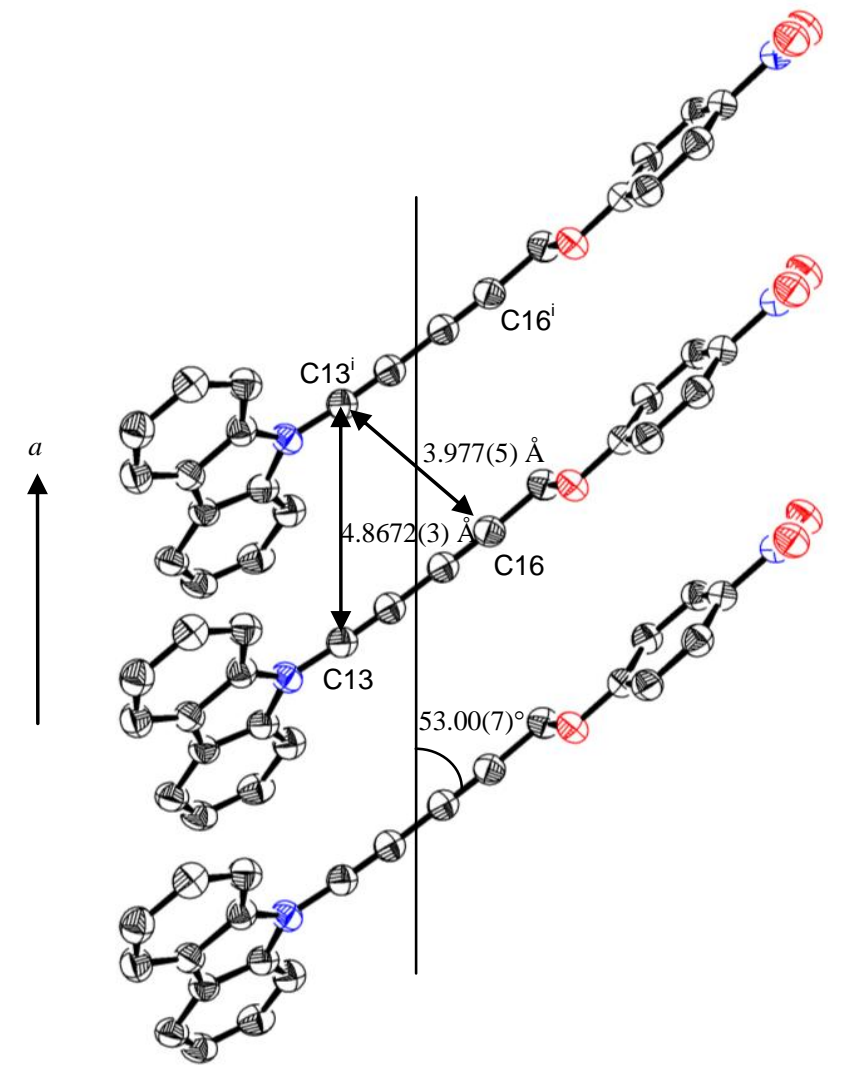

(c)

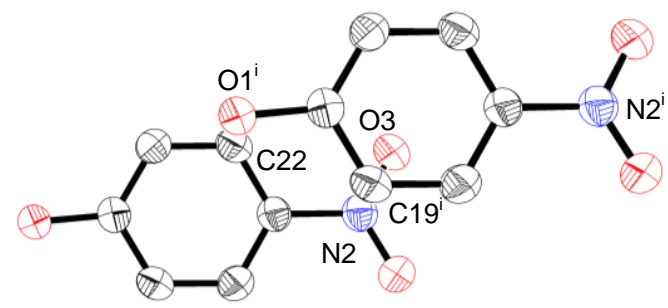

Figure 1. Crystal structure of 1-(I). (a) The asymmetric unit of 1-(I) with atom-numbering scheme. Displacement ellipsoids are drawn at the $50 \%$ probability level and hydrogen atoms are shown as small spheres. (b) Stacking structure of 1-(I) along the $a$ axis. Hydrogen atoms are omitted for clarity. (c) Stacking structure of the side chain projected onto a nitrophenyl group. [Symmetry codes: (i) $x+1, y, z$.] 
(a)

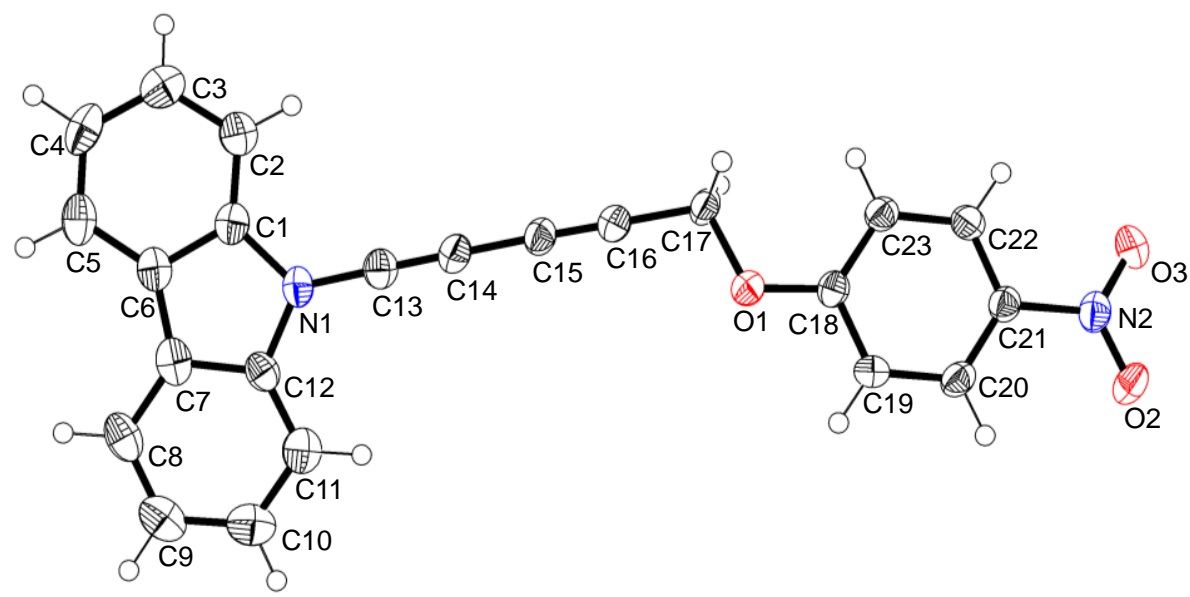

(b)

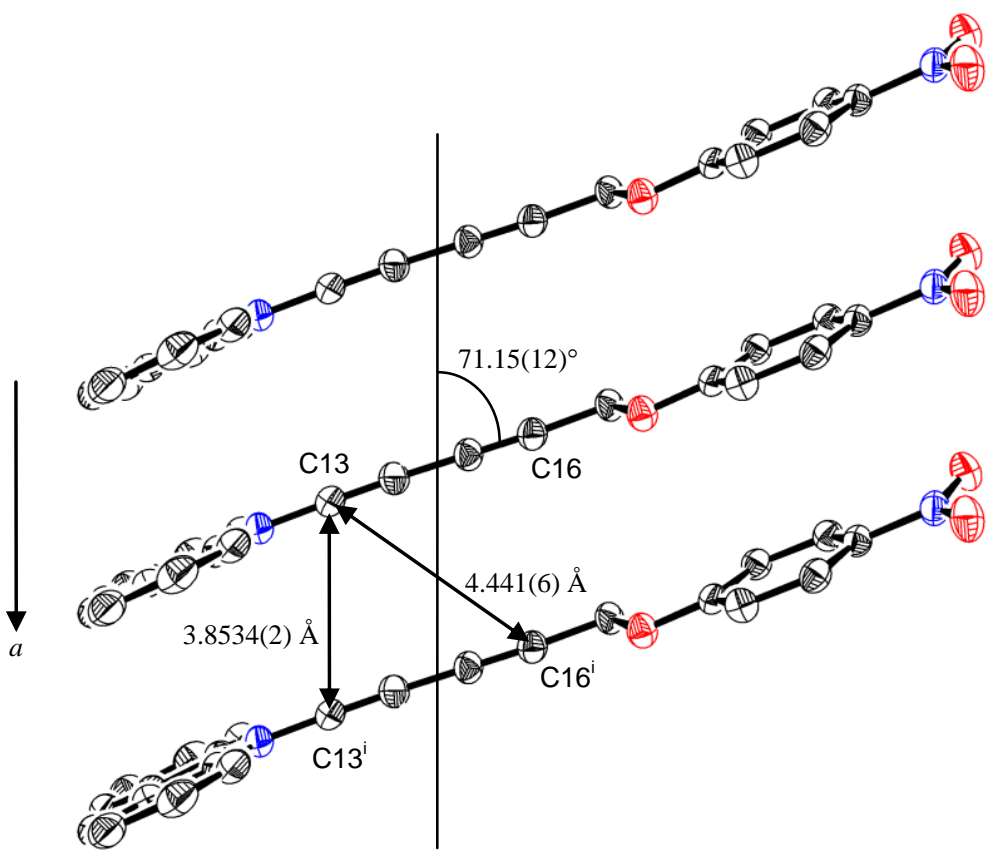

(c)

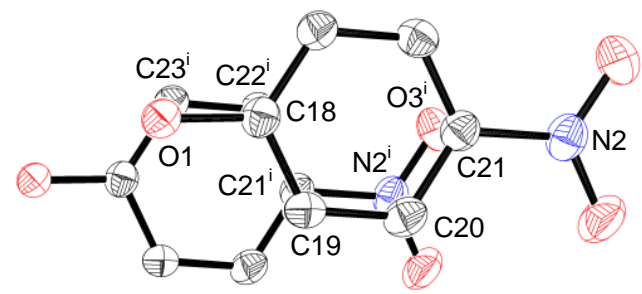

Figure 2. Crystal structure of 1-(II). (a) The asymmetric unit of 1-(II) with atom-numbering scheme. Displacement ellipsoids are drawn at the 50\% probability level and hydrogen atoms are shown as small spheres. (b) Stacking structure of 1-(II) along the $a$ axis. Hydrogen atoms are omitted for clarity. (c) Stacking structure of the side chain projected onto a nitrophenyl group. [Symmetry codes: (i) $x+1, y, z$.] 
(a)

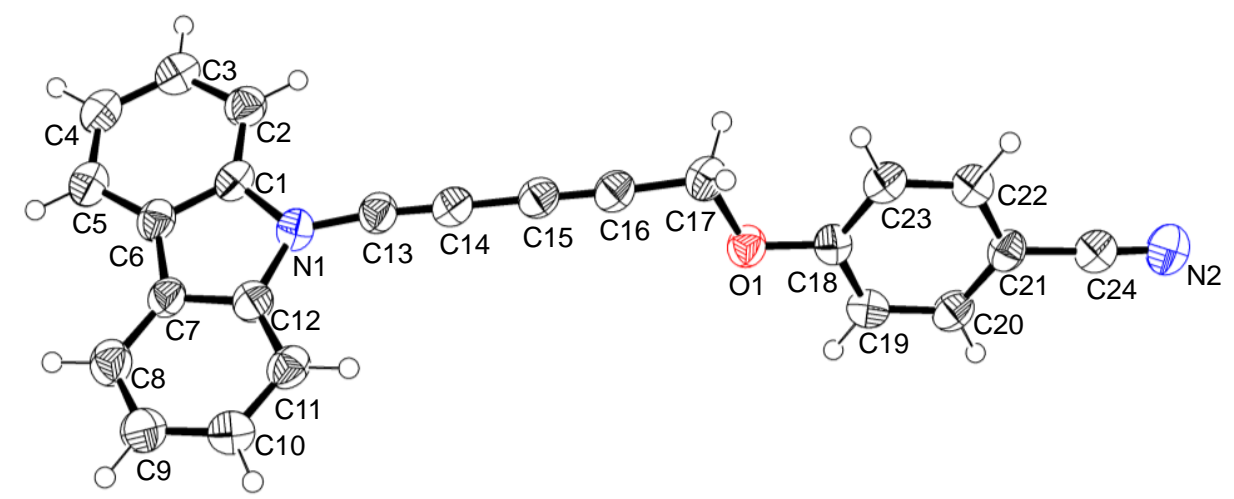

(b)

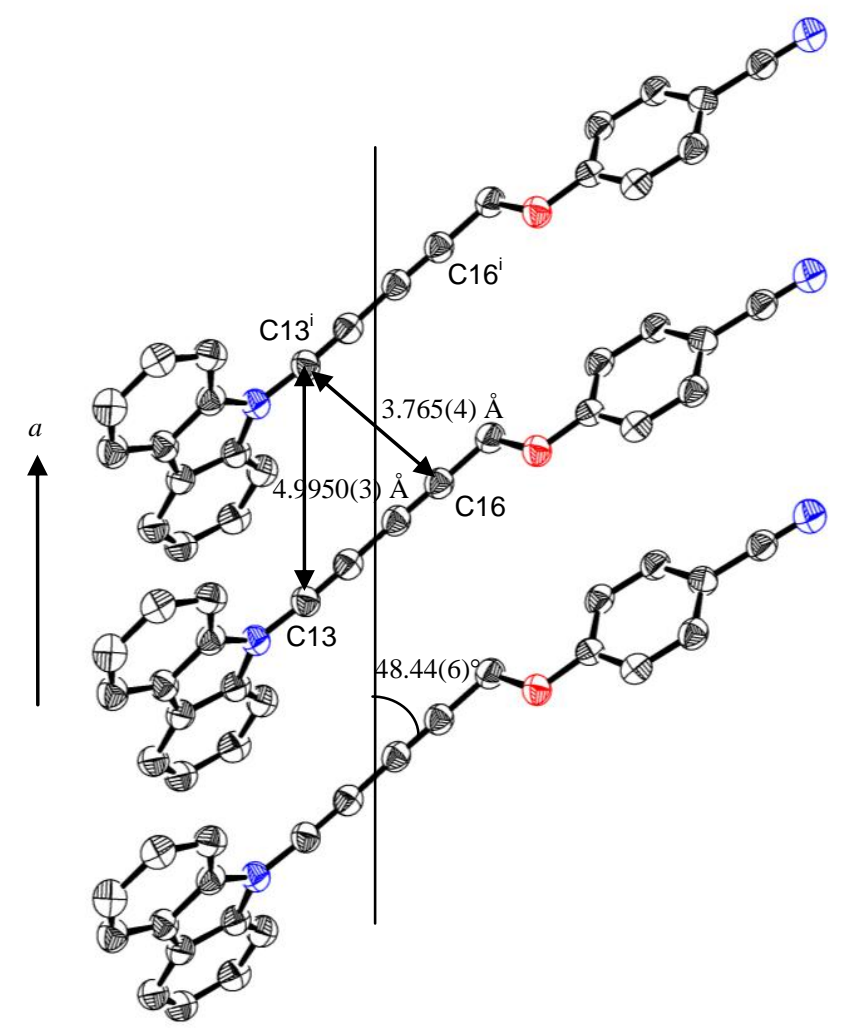

(c)

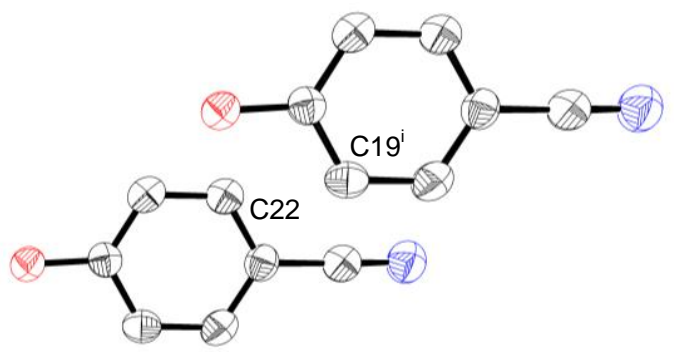

Figure 3. Crystal structure of 2. (a) The asymmetric unit of $\mathbf{2}$ with atom-numbering scheme. Displacement ellipsoids are drawn at the 50\% probability level and hydrogen atoms are shown as small spheres. (b) Stacking structure of $\mathbf{2}$ along the $a$ axis. Hydrogen atoms are omitted for clarity. (c) Stacking structure of the side chain projected onto a cyanophenyl group. [Symmetry code: (i) $x+1, y, z$.] 
(a)

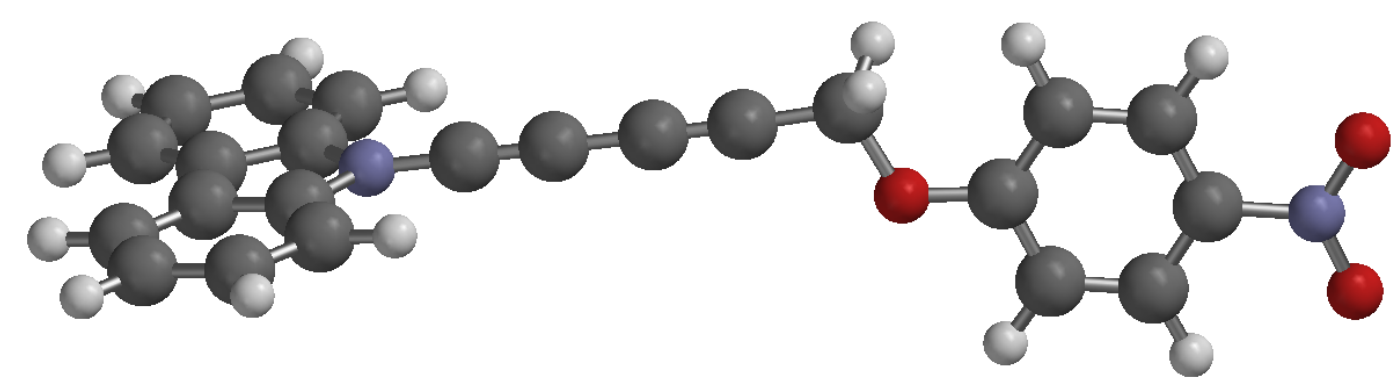

(b)

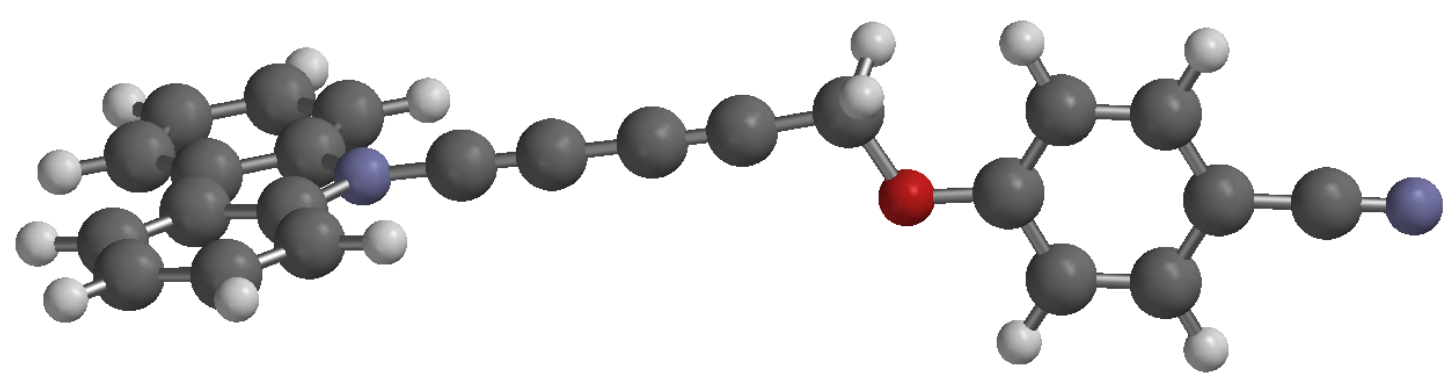

Figure 4. Optimized structure for $\mathbf{1}$ (a) and $\mathbf{2}$ (b) obtained by DFT calculations of B3LYP 6-31G(d) level. 
Scheme 1. Schematic presentation for solid-state polymerization of diacetylenes.

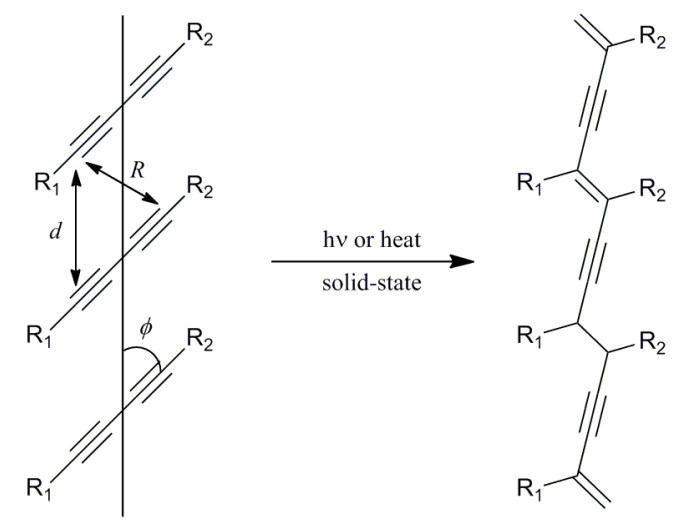


Scheme 2. Preparation of 1 and 2.
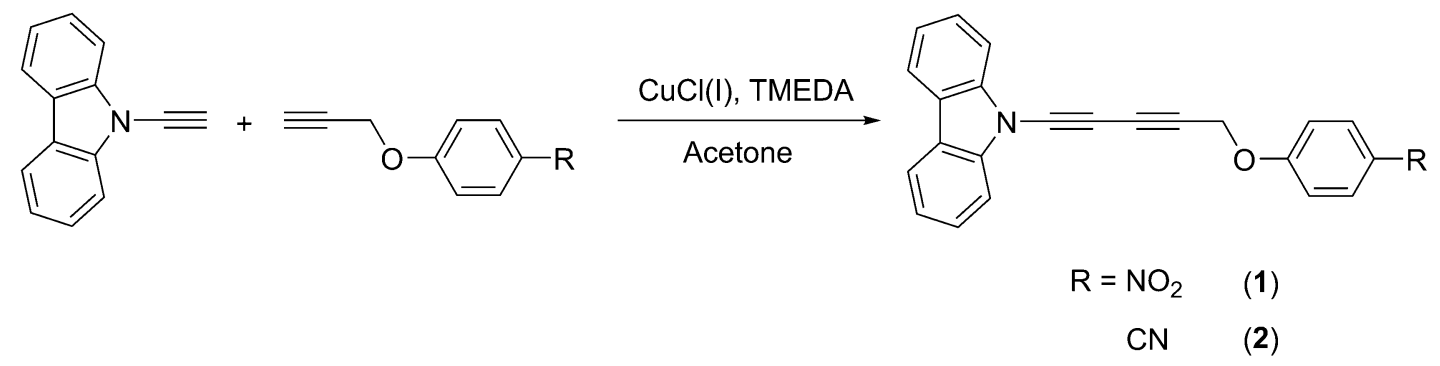
Table 1. Crystallographic data for 1-(I), 1-(II) and 2.

\begin{tabular}{|c|c|c|c|}
\hline Compound & 1-(I) & 1-(II) & 2 \\
\hline Formula & $\mathrm{C}_{23} \mathrm{H}_{14} \mathrm{~N}_{2} \mathrm{O}_{3}$ & $\mathrm{C}_{23} \mathrm{H}_{14} \mathrm{~N}_{2} \mathrm{O}_{3}$ & $\mathrm{C}_{24} \mathrm{H}_{14} \mathrm{~N}_{2} \mathrm{O}$ \\
\hline Formula Weight & 366.38 & 366.38 & 346.39 \\
\hline Temperature/K & 93 & 93 & 93 \\
\hline Radiation & $\mathrm{Cu}(\mathrm{K} \alpha) 1.54187 \AA$ & $\operatorname{Mo}(\mathrm{K} \alpha) 0.71075 \AA$ & $\mathrm{Cu}(\mathrm{K} \alpha) 1.54187 \AA$ \\
\hline Crystal System & monoclinic & orthorhombic & triclinic \\
\hline Space Group & $P 2{ }_{1} / c(\# 14)$ & $P 2{ }_{1} 2_{1} 2_{1}(\# 19)$ & $P \overline{1} \quad(\# 2)$ \\
\hline$a / \AA$ & $4.8672(3)$ & $3.8534(2)$ & $4.9950(3)$ \\
\hline$b / \AA$ & $9.4102(4)$ & $8.6365(6)$ & $9.0141(5)$ \\
\hline$c / \AA$ & $38.2479(17)$ & $51.668(3)$ & $19.1970(10)$ \\
\hline$\alpha /^{\circ}$ & 90 & 90 & $90.704(3)$ \\
\hline$\beta /^{\circ}$ & $91.461(7)$ & 90 & $94.785(3)$ \\
\hline$\gamma^{\circ}$ & 90 & 90 & $93.010(3)$ \\
\hline$V / \AA^{3}$ & $1751.24(16)$ & $1719.51(18)$ & $860.03(9)$ \\
\hline$Z$ & 4 & 4 & 2 \\
\hline$D_{\text {calc }} / \mathrm{g} \mathrm{cm}^{-3}$ & 1.389 & 1.415 & 1.337 \\
\hline$R_{1}(I>2.00 \sigma(I))$ & 0.0707 & 0.0694 & 0.0510 \\
\hline$w R_{2}$ (all data) & 0.2115 & 0.1975 & 0.1528 \\
\hline Goodness of Fit & 1.084 & 1.071 & 0.995 \\
\hline
\end{tabular}


Table 2. Selected bond lengths ( $\left.{ }^{\circ}\right)$ and angles $\left(^{\circ}\right)$ of 1-(I), 1-(II) and 2.

\begin{tabular}{|c|c|c|c|}
\hline Compound & 1-(I) & 1-(II) & 2 \\
\hline \multicolumn{4}{|c|}{ Bond lengths } \\
\hline $\mathrm{N} 1-\mathrm{C} 13$ & $1.343(4)$ & $1.341(6)$ & $1.341(3)$ \\
\hline $\mathrm{C} 13-\mathrm{C} 14$ & $1.196(5)$ & $1.203(6)$ & $1.194(4)$ \\
\hline $\mathrm{C} 14-\mathrm{C} 15$ & $1.374(5)$ & $1.386(6)$ & $1.373(4)$ \\
\hline $\mathrm{C} 15-\mathrm{C} 16$ & $1.200(5)$ & $1.192(6)$ & $1.203(4)$ \\
\hline C16-C17 & $1.460(5)$ & $1.461(6)$ & $1.451(4)$ \\
\hline $\mathrm{C} 21-\mathrm{N} 2$ & $1.462(4)$ & $1.455(6)$ & - \\
\hline $\mathrm{N} 2-\mathrm{O} 2$ & $1.232(4)$ & $1.231(5)$ & - \\
\hline $\mathrm{N} 2-\mathrm{O} 3$ & $1.239(4)$ & $1.229(5)$ & - \\
\hline $\mathrm{C} 21-\mathrm{C} 24$ & - & - & $1.429(4)$ \\
\hline $\mathrm{C} 24-\mathrm{N} 2$ & - & - & $1.158(4)$ \\
\hline \multicolumn{4}{|c|}{ Bond angles } \\
\hline $\mathrm{N} 1-\mathrm{C} 13-\mathrm{C} 14$ & $174.2(4)$ & $178.8(5)$ & $172.6(3)$ \\
\hline C13-C14-C15 & $177.3(4)$ & $178.0(5)$ & 178.3(3) \\
\hline C14-C15-C16 & $176.6(4)$ & $178.7(5)$ & $178.4(3)$ \\
\hline $\mathrm{C} 15-\mathrm{C} 16-\mathrm{C} 17$ & $177.0(4)$ & $177.4(5)$ & $177.0(3)$ \\
\hline $\mathrm{C} 21-\mathrm{N} 2-\mathrm{O} 2$ & $117.9(3)$ & $118.7(4)$ & - \\
\hline $\mathrm{C} 21-\mathrm{N} 2-\mathrm{O} 3$ & $118.9(3)$ & $118.4(4)$ & - \\
\hline $\mathrm{O} 2-\mathrm{N} 2-\mathrm{O} 3$ & 123.1(3) & $122.8(4)$ & - \\
\hline $\mathrm{C} 21-\mathrm{C} 24-\mathrm{N} 2$ & - & - & $178.1(3)$ \\
\hline
\end{tabular}

